\title{
Comparison between Powders of Strontium Hexaferrite Processed by Dynamic Gas Heat Treatment and Re-Calcination
}

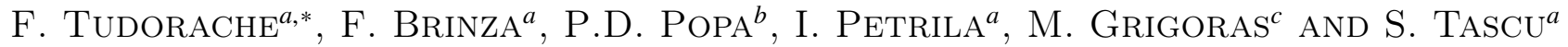 \\ ${ }^{a}$ Department of Physics, "Alexandru Ioan Cuza" University of Iasi, Blvd. Carol I, no. 11, 700506, Iasi, Romania \\ ${ }^{b}$ National Institute of R\&D for Technical Physics-IFT Iasi, Blvd. D. Mangeron, no. 47, 700050, Iasi, Romania \\ ${ }^{c}$ Petru Poni Institute of Macromolecular Chemistry, 41A, Gr. Ghica Voda Alley, 700487, Iasi, Romania
}

The utilization of classical ceramic technology for ferrite preparation permits to obtain strontium hexaferrite with big crystals, of micrometer size, with a smaller coercive force than the hexaferrite with submicron crystals. In this work the strontium hexaferrite was obtained with submicron crystals, by hot reduction of the hexaferrite obtained through ceramic technology in $\mathrm{CO}$ atmosphere, followed by the thermal re-oxidization in air. The effects of treatment in $\mathrm{CO}$ atmosphere and of the re-calcination treatment on the magnetic and electric properties of the strontium hexaferrite were investigated.

PACS: 75.50.Vv, 75.47.Lx

\section{Introduction}

The hexaferrites present a real interest from the standpoint of their applications in various domains, such as permanent magnets, magnetic storage mediums, microwaves, given their special properties: high coercivity and remanence, low manufacturing cost, chemical and thermal stability $[1-4]$.

The highest coercivity value can be obtained when the crystals have the maximum size at which they remain monodomains. One of the methods used to obtain submicron powder of strontium hexaferrite with big coercivity is the method of reduction and re-oxidization of hexaferrite powder [5].

In this work a strontium hexaferrite powder was obtained, calcined at the temperature of $1100^{\circ} \mathrm{C}$ for $1 \mathrm{~h}$, to which a hot reduction treatment in $\mathrm{CO}$ flux was applied for $1 \mathrm{~h}$ at the temperature of $900^{\circ} \mathrm{C}$, followed by re-calcination for $1 \mathrm{~h}$ at the temperature of $1000^{\circ} \mathrm{C}$.

\section{Experimental methods}

The strontium hexaferrite powder was prepared using the classical ceramic technology. The quantities of $\mathrm{Fe}_{2} \mathrm{O}_{3}$ and $\mathrm{SrO}$ with $99 \%$ purity (Merck) were weighted according to the stoichiometric formula, and they were homogenized in a ball mill for $14 \mathrm{~h}$, after which they were treated in air for $12 \mathrm{~h}$ at the temperature of $1100^{\circ} \mathrm{C}$.

\footnotetext{
* corresponding author; e-mail: florin.tudorache@uaic.ro
}

The powder was dynamically treated in a horizontal furnace in CO flow for $1 \mathrm{~h}$ at the temperature of $900^{\circ} \mathrm{C}$. The resulted powder was re-calcined in air for $1 \mathrm{~h}$ at $1000^{\circ} \mathrm{C}$.

The samples were made from the hexaferrite initially obtained at $1100^{\circ} \mathrm{C}$, as well as from the material resulting after the dynamic treatment at $900^{\circ} \mathrm{C}$ in $\mathrm{CO}$ atmosphere, and from the material resulting after re-calcination in air at $1000^{\circ} \mathrm{C}$. The samples were investigated from microstructural, magnetic and electric standpoint.

In order to use the hexaferrite in the magnetic memory applications, it needs to have the highest coercivity possible, and this can be obtained for a crystal size of $0.5-0.6 \mu \mathrm{m}$.

Three samples of strontium hexaferrite were obtained and their microstructure was investigated by X-ray diffraction, using a $\mathrm{Cu} K_{\alpha}$ anticathode, at a 4 degree/min scanning rate (Shimadzu LabX XRD-6000), and by electron microscopy.

For the measurements of remanent magnetization and coercivity, spherical samples were prepared with the diameter of 5-6 $\mathrm{mm}$. The measurements were carried out with a vibrating sample magnetometer at the temperature of $20^{\circ} \mathrm{C}$ and an applied field of $800 \mathrm{kA} / \mathrm{m}$.

In order to carry out electric investigations, the strontium ferrite powder was uniaxially pressed in shape of discs with the diameter of $10 \mathrm{~mm}$ and thickness of 2-3 mm. Silver electrodes were deposited on the both plane sample surfaces. The electric properties were investigated with Solartron 1260 A Impedance/Gain Analyser, in the frequency range $1 \div 10^{6} \mathrm{~Hz}$. 


\section{Results and discussion}

The analysis of the X-ray diffraction presented in Fig. 1 shows that the sample initially prepared at the temperature of $1100^{\circ} \mathrm{C}$ mainly contains $\mathrm{SrFe}_{12} \mathrm{O}_{19}$, and small amounts of hematite $\left(\mathrm{Fe}_{2} \mathrm{O}_{3}\right)$ and magnetite $\left(\mathrm{Fe}_{3} \mathrm{O}_{4}\right)$. After carrying out the dynamic treatment in $\mathrm{CO}$ flux for $1 \mathrm{~h}$ at $900^{\circ} \mathrm{C}$, most part of strontium hexaferrite had disappeared, being converted in $\mathrm{Fe}_{2} \mathrm{O}_{3}, \mathrm{SrO}, \mathrm{FeO}$ and $\alpha$-Fe. After re-calcination in air for $1 \mathrm{~h}$ at $1000{ }^{\circ} \mathrm{C}$, the strontium hexaferrite has completely regenerated, only small amounts of hematite and magnetite remained, similar to the initial sample.

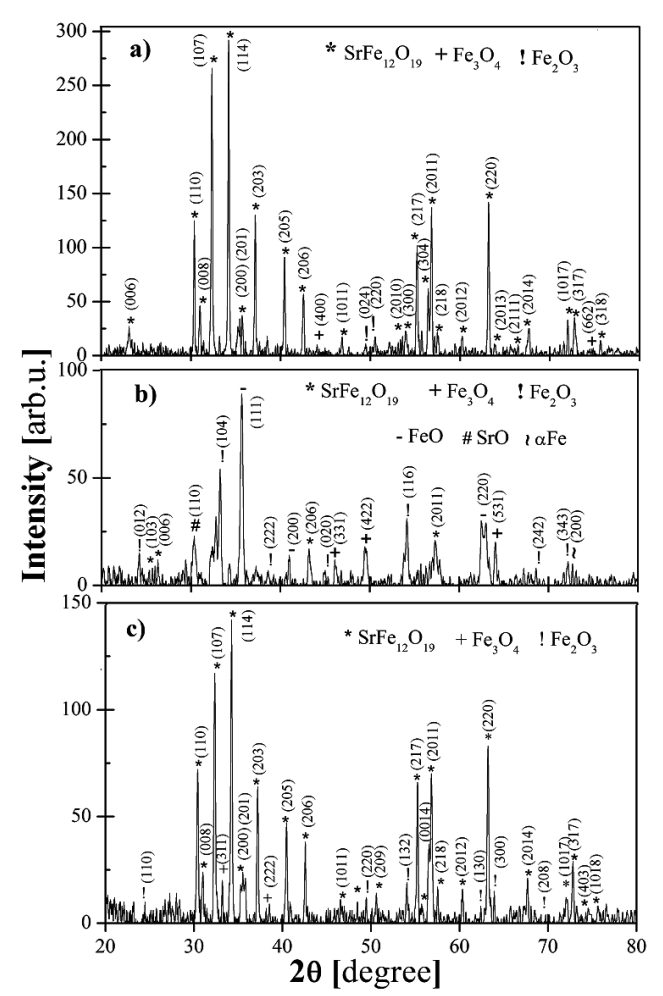

Fig. 1. X-ray diffraction patterns of the powders annealed in (a) air at $1100^{\circ} \mathrm{C}$, (b) $\mathrm{CO}$ dynamic atmospheres, (c) air at $1000^{\circ} \mathrm{C}$.

The initially obtained hexaferrite powder contains crystallites with size as big as $5-10 \mu \mathrm{m}$, Fig. 2a. After the treatment in $\mathrm{CO}$ atmosphere, spherical crystallites resulted with the mean size of $0.2 \mu \mathrm{m}$, Fig. $2 \mathrm{~b}$. After re-calcination at $1000^{\circ} \mathrm{C}$, plate crystals with the mean size of $0.5 \mu \mathrm{m}$ were formed (Fig. 2c).

The sample initially calcined at $1100^{\circ} \mathrm{C}$ is typically magnetic hard, with $H_{\mathrm{c}}=127 \mathrm{kA} / \mathrm{m}$ and $M_{\mathrm{R}} / M_{\mathrm{S}}=0.54$ (see Table I). The sample dynamically treated in $\mathrm{CO}$ atmosphere at $900^{\circ} \mathrm{C}$ is typically magnetic soft and presents a diminution of $M_{\mathrm{R}}$ and $M_{\mathrm{S}}$, as well as a drastical decrease of $H_{\mathrm{c}}$ down to $23.8 \mathrm{kA} / \mathrm{m}$. After re-calcination in air at $1000^{\circ} \mathrm{C}$, the strontium hexaferrite has higher $M_{\mathrm{R}}$ and $M_{\mathrm{S}}$, and coercivity almost twice as big as the initial sample.

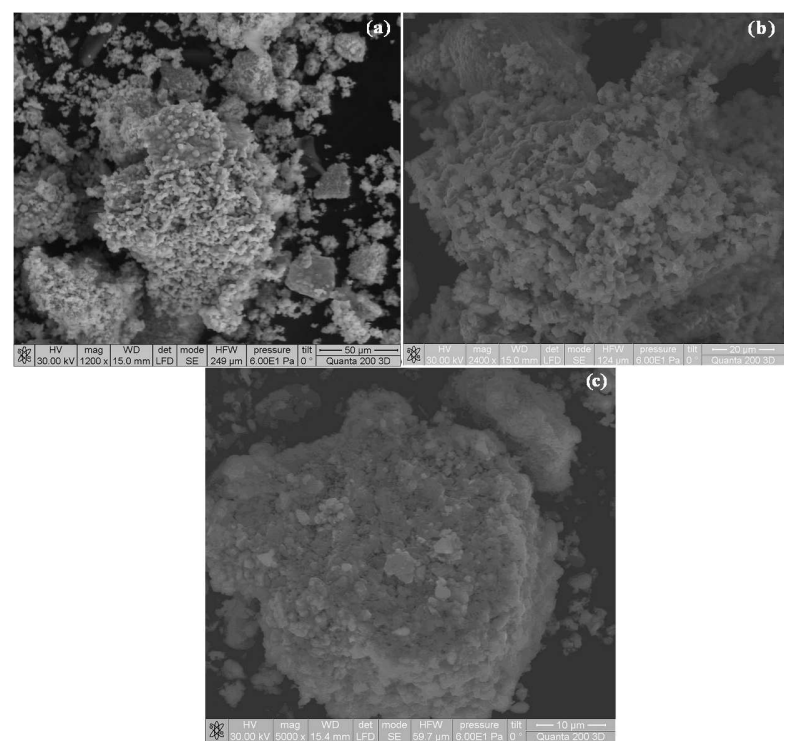

Fig. 2. SEM micrographs of (a) initial powder, (b) the powder after dynamic CO treatment, (c) the powder after re-calcination.

As the result of the electric investigation, it was found out that the sample initially treated at $1100^{\circ} \mathrm{C}$ and the sample re-calcined at $1000^{\circ} \mathrm{C}$ have similar electric properties, as can be seen from Fig. 3 and Table II. The sample dynamically treated in $\mathrm{CO}$ flow has its conductivity and dielectric losses much higher than the samples treated in air.

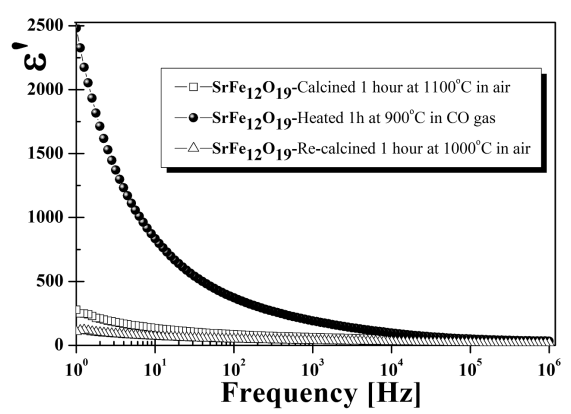

Fig. 3. Real part of permittivity vs. frequency at room temperature in $\mathrm{SrFe}_{12} \mathrm{O}_{19}$ hexaferrites.

\section{TABLE II}

Summary of the dielectrics characteristics of $\mathrm{SrFe}_{12} \mathrm{O}_{19}$ hexaferrites.

\begin{tabular}{l|c|c}
\hline \hline \multicolumn{1}{c|}{ Sample } & $\begin{array}{c}\text { Dielectric loss } \\
\text { low frequency } \\
{\left[10^{3} \mathrm{~Hz}\right]}\end{array}$ & $\begin{array}{c}\text { Conductivity } \\
{[\mathrm{S} / \mathrm{m}]}\end{array}$ \\
\hline calcined at $1100^{\circ} \mathrm{C}$ in air & 0.18 & $1.12 \times 10^{-8}$ \\
heated at $900^{\circ} \mathrm{C}$ in $\mathrm{CO}$ & 0.55 & $6.27 \times 10^{-7}$ \\
re-calcined at $1000^{\circ} \mathrm{C}$ in air & 0.17 & $2.87 \times 10^{-9}$
\end{tabular}


Summary of the magnetic properties of strontium hexaferrites.

\begin{tabular}{l|c|c|c}
\hline \hline \multicolumn{1}{c|}{ Sample } & $\begin{array}{c}\text { Coercivity } \\
H_{\mathrm{c}}[\mathrm{kA} / \mathrm{m}]\end{array}$ & $\begin{array}{c}\text { Saturation } \\
\text { magnetization } \\
M_{\mathrm{S}}[\mathrm{emu} / \mathrm{g}]\end{array}$ & $\begin{array}{c}\text { Remanence } \\
M_{\mathrm{R}}[\mathrm{emu} / \mathrm{g}]\end{array}$ \\
\hline calcined at $1100^{\circ} \mathrm{C}$ in air & 127 & 42.2 & 25.7 \\
heated at $900^{\circ} \mathrm{C}$ in $\mathrm{CO}$ & 23.8 & 39.9 & 15.4 \\
re-calcined at $1000^{\circ} \mathrm{C}$ in air & 214 & 48.1 & 28.1
\end{tabular}

\section{Conclusions}

By reduction in $\mathrm{CO}$ flow and re-oxidization, the strontium hexaferrite preserves its composition and electric properties, a controlled diminution of its crystal size and an important improvement of its magnetic properties take place.

The treatment of $\mathrm{SrFe}_{12} \mathrm{O}_{19}$ in $\mathrm{CO}$ atmosphere for $1 \mathrm{~h}$ at $900{ }^{\circ} \mathrm{C}$ resulted in:

- decomposition of $\mathrm{SrFe}_{12} \mathrm{O}_{19}$ in $\alpha$-Fe, FeO and $\mathrm{SrO}$; increase of conductivity and dielectric loss;

- crystallite diminution and loss of hard magnetic character, through the noticeable decrease of $H_{\mathrm{c}}$ and of $M_{\mathrm{R}}$.

The re-calcination in air for $1 \mathrm{~h}$ at $1000^{\circ} \mathrm{C}$ resulted in:

- complete regeneration of $\mathrm{SrFe}_{12} \mathrm{O}_{19}$, noticeable decrease of conductivity and dielectric loss;

- crystallite growth at optimum size and improvement of hard magnetic properties, as compared to the initial hexaferrite.

The presented method permits to obtain submicron hexaferrite powder, with applications in magnetic memory media.

\section{Acknowledgments}

Authors are grateful to "Research Center on Advanced Materials and Technologies - RAMTECH" created within the framework 162/15.06.2010 of POS CCEA2-O2.1.2, where these measurements have been done.

Researches of Florin Brinza were supported by grant no. 72-191/2008 NUCNANO, MECTS-CNMP Romania.

Mircea Grigoras thanks the Romanian National Authority for Scientific Research for financial support (grant PN II IDEI, code ID-997/2008 and ID-993/2008).

\section{References}

[1] Y.M. Sun, W.Q. Yu, Z. Hua, Acta Phys. Pol. A 119, 374 (2011).

[2] J. Fang, J. Wang, L.-M. Gan, S.-C. Ng, J. Ding, X. Liu, J. Am. Ceram. Soc. 83, 1049 (2000).

[3] C. Doroftei, E. Rezlescu, N. Rezlescu, F. Tudorache, P.D. Popa, J. Optoelectron Adv. M. 10, 2919 (2008).

[4] Z. Surowiec, W. Gac, M. Wiertel, Acta Phys. Pol. A 119, 18 (2011).

[5] F. Tudorache, E. Rezlescu, P.D. Popa, N. Rezlescu, J. Optoelectron Adv. M. 10, 1889 (2008). 